\title{
The Economic Impact of the Creative Industry in the European Union
}

\author{
Rafael Boix-Domènech and Pau Rausell-Köster
}

\begin{abstract}
This work analyses the economic impact of the creative industry in the European Union. The paper quantifies the direct and indirect impacts of the creative industry, concluding that they not only have a direct impact on the employment and the production, but also contributes to the technological progress and long-term development of the European Union. Most of this contribution is due to the creative service industries, whereas the direct contribution of the creative manufacturing industries is smaller.
\end{abstract}

\section{Introduction}

Now is the time to admit that the relationships between the creative ecosystem and the economic model are much more sophisticated than we previously thought and that they are connected in ways that go way beyond market exchanges.

In this paper, we ask what the impact is of the creative industries on the European Union (EU) economy. The creative industries contribute more than many traditional industries to the macroeconomic indicators of the EU, such as the production or the employment. However, the hypothesis we explore is that impact of the creative industries in the UE economy goes further than being a mere contribution to employment and production, and that they contribute to the technological progress and long-term development of the EU.

The role of the creative industries as a driver of innovation and a catalyst for economic transformation has become increasingly important in European regional policy. The new European regional policy (Foray et al. 2012) notes that the creative industries and, in particular, the creative services are in a strategic position to promote smart, sustainable and inclusive growth in all EU regions and cities, and

\author{
R. Boix-Domènech $(\bowtie)$ \\ Department of Economic Structure, Universitat de València, València, Spain \\ e-mail: Rafael.boix@uv.es \\ P. Rausell-Köster \\ Department of Applied Economics, Universitat de València, València, Spain
}


thus contribute fully to the Europe 2020 Strategy. The Research and Innovation Strategies (RIS3) guide argues that creative industries have multiple roles to play in unlocking the creative and innovative potential of a region (Foray et al. 2012). Also, the academic literature advocates the promotion of a sustainable and endogenous way of resetting an economy through a growth agenda that includes a role for creative industries in regional and local contexts (Cooke and De Propris 2011).

But the relations between cultural and creative sectors and the economic model go much further. The cultural field produces values, and values are one of the elements that determine our behaviour and govern the way we perceive the world. In fact, it is our set of values that sets the objectives of the institutions we create in order to articulate our life in society. The field of culture externalises values that permeate into the socio-economic space and seem to be much more in line with the concept of sustainable development. In terms of Ingleharts's Cultural Evolution, increasing emphasis in Posmaterialism values and Self-expression values (Inglehart 2018). Values emerging from the field of culture reflect a new hierarchy that includes aspects like the explicit wish to innovate, relational consumerism (as opposed to transactional consumerism), free exchange, critical thinking, personal development, solidarity, cooperation, networking, the value of diversity and beauty, participation and the importance of the recreational and vital dimension, as opposed to the purely economic gain. In other words, the actions of creativity are not exclusively guided by instrumental rationality. Expressive values and values of exchange and mutual benefit are also at work.

The goal of this paper is to provide a critical review of the literature about the direct and total impacts of the creative industries in the economy of the EU. The paper contributes to the literature by providing the most complete review of these effects elaborated to date, and by comparing the size of the direct effects with the total effects (direct, indirect and induced).

The paper is divided into five parts. Section 2 reviews the definition and measurement of the creative industries. Section 3 focuses on the scenarios and theoretical models to explore the economic impact of the creative industries. Section 4 reviews the direct and total effects of the creative industries on the EU economy in the literature, and how they change regarding the definition of creative industries used and the statistical models used for their measurement. Finally, Sect. 5 summarises and discusses the results.

\section{The Creative Industries: Definition and Measurement}

\subsection{Concepts}

The term creative industries originates in Australia (DCA 1994), and then its use expanded to the United Kingdom, which needed to find new bases for growth for its post-industrial economy (DCMS 1998; O'Connor 2007). They are also frequently 
referred to as cultural and creative industries, the creative industry, or the creative sector, even if some authors introduce nuances in the use of one or the other term.

There are many definitions of creative industries. The most usually cited are those by the British Department of Culture Media and Sports (DCMS), the United Nations Conference for Trade and Development (UNCTAD), and the European Union authorities (European Commission, European Parliament):

(a) The DCMS (2001: 5) refers to "industries which have their origin in individual creativity, skill and talent and which have a potential for wealth and job creation through the generation and exploitation of intellectual property". Creative industries are signs of the natural evolution of the cultural industry that follow the structural changes caused by the affirmation of new technologies and new products in the sphere of the entertainment industry.

(b) UNCTAD (2008: 4) defines creative industries as "cycles of creation, production and distribution of goods and services that use creativity and intellectual capital as primary inputs; constitute a set of knowledge-based activities, focused on but not limited to arts, potentially generating revenues from trade and intellectual property rights; comprise tangible products and intangible intellectual or artistic services with creative content, economic value and market objectives; are at the cross-road among the artisan, services and industrial sectors; and constitute a new dynamic sector in the world trade". The term "creative industries" exceeds the limits of the cultural sector to include media and ICTs following the structural changes due to the growth and development of the new technologies.

(c) For the European Parliament (2016: 10) they are defined as "those industries that are based on cultural values, cultural diversity, individual and/or collective creativity, skills and talent with the potential to generate innovation, wealth and jobs through the creation of social and economic value, in particular from intellectual property".

\subsection{Measurement}

The concept of creative industries is made operational by drawing up a list of activities in which creativity is particularly important. So far there is no agreement on which of the approaches to reach this list is the most appropriate or what activities should be classified as creative (UNCTAD 2008; Throsby 2008).

UNCTAD $(2008,2010)$ distinguishes five conceptual models for its definition:

(a) the DCMS model, based on individual creativity and that marks the relevance of technological creative industries in contrast to the traditional cultural industries;

(b) the symbolic texts model differentiates between central, peripheral and border cultural industries, and focuses on the processes through which thought culture and creativity are produced, disseminated and transmitted;

(c) the concentric circle model assumes that the creative capacity and content is different in each industry. Creative ideas originate in a core creative circle 
formed by the creative arts, which then diffuse outwards through a series of concentric circles in which the amount of creative content decreases successively: other core industries, less central industries, and related industries;

(d) the copyright model of World Intellectual Property Organization (WIPO) and International Intellectual Property Alliance (IIPA) distinguishes between industries that produce most of the intellectual property (core copyright industries), those necessary to convey the goods and services to the consumer (interdependent copyright industries), and those in which intellectual property is only a minor part (partial copyright industries);

(e) and the UNCTAD model, which attempts to classify creative industries into domains, groups and subsectors, distinguishing between heritage, arts, media and functional creations. This model differentiates between upstream activities (traditional cultural activities), and downstream activities (much closer to the market).

Other research has proposed to classify an industry as creative based on its share of creative occupations or/and the qualification in terms of educational levels of the employees (Higgs and Cunningham 2008; Nathan et al. 2015 for NESTA (2015)).

The choice of one or the other approach and the delimitation of the following list of sectors to measure the creative industries usually provokes controversy and not only a few arguments. The most comprehensive list seems to be the provided by UNCTAD (2010), including: printing (only for statistical comparisons where data are not enough disaggregated), publishing, advertising and related services, architecture and engineering, specialised trade of art in antique markets, crafts, fashion and high-end industries, specialised design services, film, motion and video, musing and sound recording, performing arts, other visual arts, photography, radio and television broadcasting, software and videogames, heritage and cultural occupations, copyright collecting societies, cultural tourism and creative research and development (R\&D).

However, as can be seen in Table 1, other classifications do not consider industries such as printing, creative retail trade, crafts, designer fashion, heritage, interactive media, some visual arts, copyright societies, cultural tourism, recreational services, engineering and R\&D services.

Since most of the industries are shared between the most usual classifications (see Throsby 2008), differences resulting from the application of one classification or another can be moderate, and their importance depends on the objective of the research and the places to which they are applied (see Lazzeretti et al. 2018). For example, Boix et al. (2013) and Boix and Soler (2017) argue that manufacturing sectors usually classified as creative are basically engaged in making more than in creating, and their inclusion biases the results of the estimation of the impacts of the creative industries, so that they should be better focused as semi-creative industries (Boix 2012).

Although the use of standard lists is useful in comparisons (in particular between cities, regions and countries), it is still debatable whether the same economic sector can be creative in one place and not in another. In addition, the classifications are 


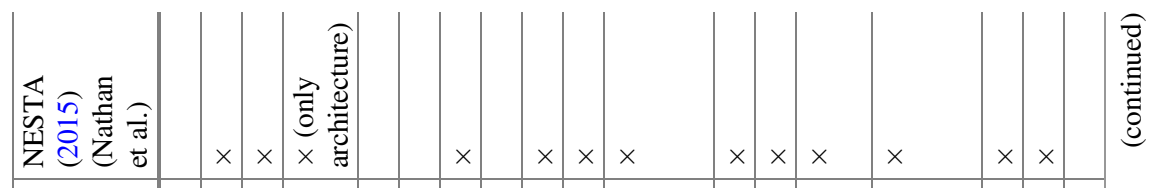

0
0
0
0
0
0
0
0
0
0
0
0
0
0
0
0
0
0
0
0
0
0
0
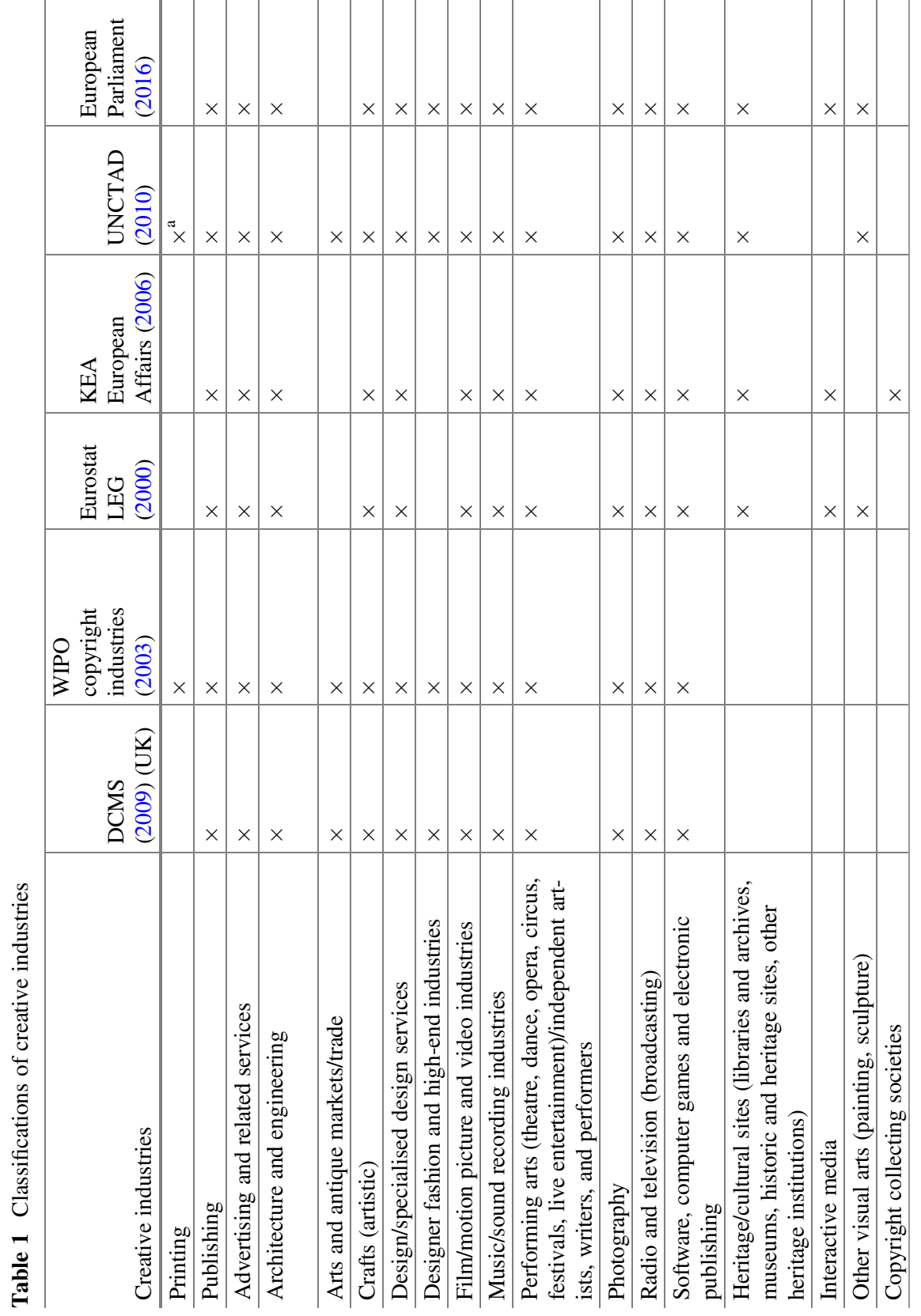


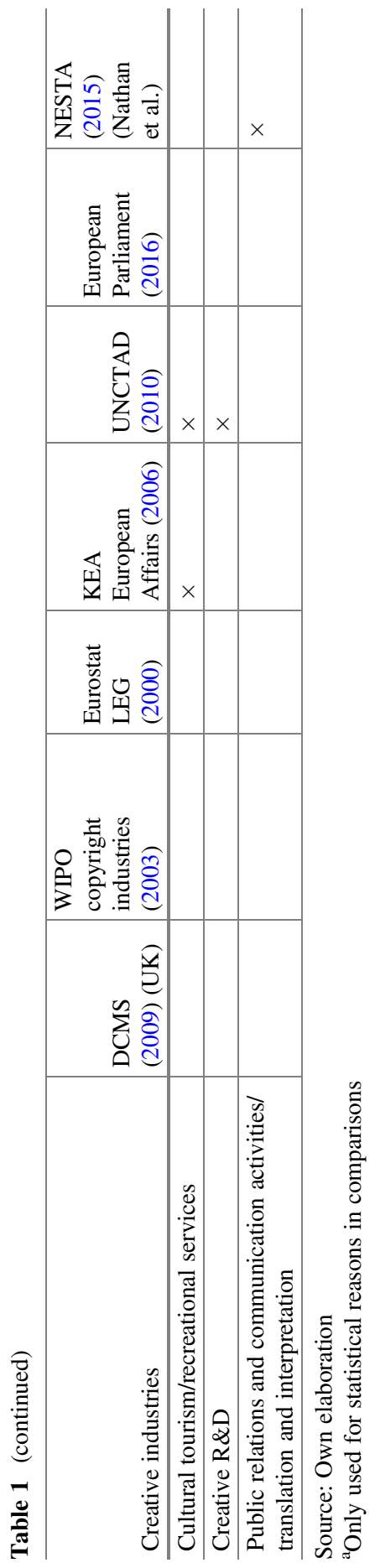


updated over time, trying to introduce more objective criteria for the delimitation of sectors, as discussed by Nathan et al. (2015).

\subsection{European Statistics for the Creative Sectors}

Due to the dual nature of the creative sector, the statistics for its measurement can focus on the purely cultural or purely technological part when a restricted version of creativity is adopted.

Focusing on a more cultural approach, a precursor is the "Framework for Culture Statistics" (FCS), adopted at the Conference of European Statisticians of 1986 (see UNESCO 2009). The guiding principles included in the 2009 FCS are aimed at establishing a conceptual foundation that encompasses all cultural expressions and uses internationally comparable categories for the classification of products, economic activities and occupations, facilitating the identification of variables and the elaboration of cultural indicators to capture the cultural reality in a way that is both descriptive and integrating (Coll et al. 2018). The guidelines were applied to the elaboration of world cultural statistics in UNESCO (2012).

An increase in the level of awareness about the lack of cultural statistics in the European Union (EU) in the context of several international forums led to the establishment of the European Leadership Group on Cultural Statistics (LEG-Cultura) in 1997. The main goal of the LEG was to define the cultural domains, suggest changes to national and international classifications to reflect the distinctive features of the cultural and creative sector, revise and carry out an inventory of all the available data and create a series of indicators that allowed comparison between nations.

In 2009, Eurostat proposed the creation of the European Statistical Network (ESSnet-Culture) to improve the methodology and production of data about cultural sectors, and at the same time facilitate their comparison at the European level. The results were published in the form of a Cultural Statistics pocketbook (2007, 2011 and 2016) as part of the Statistical Books series. This was the first publication by Eurostat related to the field of culture that includes comparable data available in the European Statistical System and other sources of information such as UNESCO or the Eurobarometer. The data included in the Eurostat's Culture Statistics report and their original sources are: cultural employment (EU Labour Force Survey), cultural enterprises (Business Statistics and Business Demography), international trade in cultural goods (Eurostat), cultural participation (Adult Education Survey by Eurostat), use of ICT for cultural purpose (Community survey on ICT usage in households), and private spending in culture (Household Budget Survey).

At the opposite extreme, we find the reports and statistics elaborated by WIPO (2014) and the European Union Intellectual Property Office (EUIPO 2016), which focus on the intellectual property rights (IPR) part of the creative industries. This includes industries that register trademarks, patents, designs, copyright, geographical indications and plant variety rights, which means that some cultural industries 
(e.g. those related to heritage) are not considered. Both extremes-culture-based and IPR-based industries - have a part in common, and consider core definitions and enhanced perimeters.

Between these two extremes, other databases containing information on creative industries in the EU have been drawn up, using Eurostat or other public institutions as the original source of data. These include the European Cluster Observatory (ECO) (http://www.clusterobservatory.eu/) and the Toolkit of Creative Med (ToCM) (http://toolkit.creativemed.eu/). The ECO database has information for the period 1991-2011 (the quality and coverage of the information is uneven between years), at different territorial levels (NUTS 0 to NUTS 2), and considers as creative and cultural industries: advertising, artistic and literary creation, preservation of historical sites and buildings, other printing and publishing, radio and television, creative retail and distribution and software.

The ToCM is oriented towards the elaboration of policies based on creativity in the Mediterranean area of the EU, although the database contains information for all of the EU. The database is at NUTS 2 level and mainly refers to the year 2011. Data on workers in cultural and creative industries are taken from the ECO, although ToCM also includes indicators of semi-creative industries, creative class and cultural resources. It is already capable of automatically generating diagnoses and suggesting policies for each region, within the framework of the strategy RIS3.

Despite the effort made in recent times to improve the quantity and quality of creative industries' statistics, there is no doubt that more sophisticated measurement systems are needed if we are to gauge and analyse all the sophisticated relationships between the creative industries and their economic and social impacts.

\section{The Economic Impact of the Creative Industries: Scenarios and Theoretical Models}

\subsection{Scenarios}

The economic impact of the creative industries on the European Union can be analysed in terms of direct contribution to the production, employment, productivity, innovation, entrepreneurship, etc. In addition to this contribution, the most important effect of the creative industries can be found in its indirect effects, that is, its multiplying effects on the economy. In addition, other two issues should be taken into account: first, that these direct and indirect effects could be positive or negative; and second, that the intensity and direction of the effect could be different between locations.

General scenarios relating the creative industries to economic performance have been proposed by Potts and Cunningham (2008). They propose four scenarios: welfare, competitive, growth and innovation: 
(a) In the welfare model, the creative industries are deemed to be affected by Baumol's disease (Baumol and Bowen 1965) and their productivity grows at a slower rate than does the rest of the economy, even if they are subsidised. This is because in this model the creative industries are oriented to the enhancement of welfare.

(b) In the competitive model, the creative industries are seen as just another industry and have no more effect on technological change, innovation or productivity than do any other activities.

(c) In the growth model, the creative industries are said to be a growth driver and their impact on the economy is more than proportional and caused by both demand and supply influences. Demand influences occur when production or income growth results in increased demand for creative services, which, in turn, feed into and change production, or incomes, multiplying final effects (Potts and Cunningham 2008; Rausell et al., 2011). Supply-side influences can be conceptualised as occurring through five basic mechanisms through which creative industries act as a growth driver:

(c.1) First, there is a sectoral effect (Potts 2009; Lee 2014): creative industries have been growing more than other industries simply because they have been in an expansion phase, caused by increased investment and qualitative improvement in supply and input factors, institutional change and intra-sector externalities.

(c.2) Second, there is an industry spillover through supply-chain linkages into other sectors (Bakshi and McVittie 2009; UNCTAD 2010; Lee 2014).

(c.3) Third, there is the effect of improving the technical efficiency of the aggregate economy (Yu et al. 2014).

(c.4) Fourth, a knowledge spillover effect (Potts and Cunningham 2008; Bakshi and McVittie 2009; Chapain et al. 2010) occurs thanks to the introduction of new ideas that spread to other sectors, acting as a catalyst for the generation of innovations, and improving the absorptive capability of innovations in other sectors.

(c.5) And, finally, there is the supply-side effect of creating an amenity value that attracts skilled workers and tourists (Lee 2014).

(d) Finally, in the innovation model the creative industries are seen as being a part of a process of economic evolution and their role is to provide evolutionary services to the innovation system, facilitating change of the entire economic system (see Potts 2009).

The innovation model is supported by the theory of differentiated knowledge bases (Asheim et al. 2011; Asheim and Parrilli 2012). Analytical and synthetic knowledge bases are well-known in economics: the term analytical knowledge base refers to the development of new knowledge through the use of the deductive scientific method and scientific laws (e.g. the pharmaceutical industry has an analytical knowledge base), and the term synthetic knowledge base refers to the 
generation of knowledge by an inductive process of testing, experimentation, and practical work (e.g. the mechanical engineering industry develops on a synthetic knowledge base).

Of particular interest has been the introduction of a third category, the symbolic knowledge base. This type is normal for the cultural and creative industries in that it refers to the "creation of meaning and desire as well as aesthetic attributes of products, producing designs, images and symbols, and to the economic use of such forms of cultural artefacts" (Asheim et al. 2011). In the case of the symbolic base, knowledge inputs and outputs are aesthetic more than cognitive, and new knowledge is usually developed through a creative process rather than through analytical or problem-solving processes. Creative industries provide services to the rest of the productive system in two ways: as inputs to other industries, and also via a horizontal spillover effect on the perceptions of people, businesses and institutions.

Note that in these four scenarios the effects of the creative industries are basically neutral or have some positive aspect. A fifth scenario can be added, in which the effects of the creative industries on wealth and welfare are negative. This effect could be due to several causes, among them:

(a) a crowding out effect of the creative industries on other economic activities, in the case that the creative industries do not have significant impacts on welfare, or this effect exceed the initial increases in welfare considered by Baumol and Bowen (1965);

(b) the precariousness of the labour relations model that seems to accompany this type of industry (Hesmondhalgh, 2010);

(c) or effects of trivialisation, alienation or propaganda as initially considered by Horkheimer and Adorno in the Dialectic of Enlightenment (2002), and that produced a long-term joint crowding out effect on wealth and a reduction of freedoms.

\subsection{Theoretical Models}

Sacco and Segre (2006), Rausell et al. (2011), Marco et al. (2014) and Boix and Soler (2017) have developed analytical models that relate the creative industries with wealth, productivity and well-being.

Sacco and Segre (2006) propose a virtuous circle based on the acquisition of competences, where the notion of competence refers to the effect of the stimulus of cultural, symbolic and identitarian capital. The basic assumption is that the level of competence and capability of consumers (some of which are creative workers) is sufficient enough to guarantee that they would be willing to pay extra for the creative component of a product. In order to meet this demand, firms invest in the skills of creative workers in order to increase the creative component in the enterprise's goods and services. The result is an increase in a locality's stock of creative capital. Such changes in local cultural supply and rising social awareness lead to improvements in the competences of non-core creative workers while fostering demand for 
creative commodities. At this point, a part of the value added generated by the process is then devoted by firms to financing creative activities and by the public sector in investing in creative industries, creating a virtuous cycle.

Rausell et al. (2011) and Marco et al. (2014) propose a theoretical framework with circular causal effects: an increase in GDP per capita increases the share of people with high levels of education and income, the percentage of public and private expenditure oriented to creative goods and services and the stock of cultural capital. The result is an increase in the demand for creative goods and services that then engenders a growth in the share of workers in the creative industries. This has two effects. First, there is an increase in an economy's overall number of innovations due to, on the one hand, the addition of those innovations produced by the creative industries (supply side), and, on the other hand, a higher propensity to consume innovations by workers employed in the creative industries (demand side). Second, there is an increase in the level of productivity of the economy as a whole, under the assumption that productivity in the creative industries is higher than the average for the economy. Increases in innovation and productivity result in an increase in GDP per capita, and so the process starts again.

Boix and Soler (2017) address the lack of robust analytical modelling of previous research on the effects of creative industries and use a semi-endogenous technological change model to analyse the relationship between creative industries and regional productivity. The model assumes that the creative industries lead to an increase in product variety that raises productivity by allowing the spread of intermediate production more thinly across a larger number of activities, each of which is subject to diminishing returns and hence exhibits a higher average output when operated at a lower intensity. The implication is that the way to increase productivity levels is by dedicating a large fraction of output to creative activities.

\section{Measuring the Economic Impact of the Creative Industries in the European Union}

As explained in Sect. 3, the empirical research that has measured the impacts of creative industries has focused on their direct and total effects on production, income, wages, employment, productivity or innovation. The size of this effect depends to a great extent on which sectors have been included in the empirical definition of the creative industries.

\subsection{Direct Impact of the Creative Industries}

The initial reports by the Department of Culture, Media and Sports stated that at the end of the twentieth century, the creative industries were bringing about $8 \%$ of 
national income, employing 5\% of the workforce in the United Kingdom and growing at $8 \%$ per year.

Reports based on a culture-based approach (e.g. KEA 2006; Power and Nielsén 2010) and including both manufacturing and service creative industries, stated that the size of the creative sector is about $2.6 \%$ of the EU Gross Domestic Product (GDP) and employment (from 4.7 to 6.7 million employees, depending on the countries included in each report), with a turnover of 654,000 million $€$ and growth rates of the GDP and employment of more than $4 \%$ annual average.

Later studies based on more comprehensive and services-oriented definitions of the creative sector suggest that their contribution to the economy is substantially greater. TERA $(2010,2012)$ stated that core creative industries accounted for $3.8 \%$ of the workforce and $4.5 \%$ of the value added in the EU, and core plus non-core creative industries were about $6.5 \%$ of the employment (14.4 million employees in 2008 and 14 million in 2011) and 6.9\% of the EU value added. EY (2014) stated a contribution of the creative industries to the EU economy of 535.9 billion $€, 4.2 \%$ of the GDP and 3.3\% of the EU's active population (7.1 million employees). These reports also stated that until 2007, the creative industries were a fast-growing sector, and that after 2008 they withstood the economic crisis.

A recent research by Boix and Soler (2017) measured the size of the creative industries for 250 regions in 24 countries of the $\mathrm{EU}$, finding that creative industries generated $7.8 \%$ of the total production (GDP), $7.9 \%$ of total employment, and that their labour productivity was $1.2 \%$ lower than the European average. The authors find important differences between manufacturing and service creative industries, basically a low contribution and impact of creative manufacturing and a high contribution and impact of creative services. Thus, creative manufacturing was $1 \%$ of the GDP and $1.6 \%$ of the employment, and their productivity was $41 \%$ below the European average. Creative services were $6.8 \%$ of the GDP and $6.2 \%$ of the employment, and their productivity was $9 \%$ higher than the European average.

All this evidence is consistent with research for outside Europe. For example, Dolfman et al. (2007) found that in the United States the average wage in the creative industries was $34.9 \%$ higher than the national average private sector wage. Potts and Cunningham (2008) provided evidence that in Australia the average incomes of workers in the creative industries were $31 \%$ higher than national average incomes, and that the aggregate growth rate of creative industry incomes was higher than incomes for the aggregate economy.

\subsection{Spillovers and Total Effects of the Creative Industries}

There are several ways to measure the total effect of the creative industries in the economies. A traditional way, widely used in the economy of culture, has been the use of input-output tables and multipliers (Throsby 2008), although this approach has not yet been applied to the EU as a whole. 
Another way is the use of econometric models, which have been used to assess the impact of the creative industries in the economy of a single country (Rausell et al. 2011; Lee 2014) or in the regions of the EU (De-Miguel-Molina et al. 2012; Marco et al. 2014; Boix et al. 2013; Boix and Soler 2017; Boix and Peiró 2017) (see Table 2).

For a single country, Rausell et al. (2011) find that an increase of $100 \%$ in the share of creative industries is associated with an increase in GDP per capita of the Spanish regions of about $40 \%$, although their estimates did not take account of some controls. Lee (2014) finds that in the UK travel-to-work areas, the creative industries are associated with positive differences in wages relative to other sectors of the economy, showing a relative effect of between $4.7 \%$ and $6.6 \%$ for each $100 \%$ increase of employment in the creative industries.

For a wider sample covering most of the European regions, De-Miguel-Molina et al. (2012), Marco et al. (2014) and Boix et al. (2013) found that the relative effect of the creative industries on the differences in GDP per capita was between $39 \%$ and $44 \%$. However, Boix and Soler (2017) observed that these high elasticities were due to the misspecification of the empirical models, and departing from a theoretically robust semi-endogenous growth model amended the results of previous research on European regions. They found that the effect of creative industries on productivity was much lower than previously thought, with elasticities from $4 \%$ to $13 \%$. These results were confirmed by Boix and Peiró (2017).

In a similar range are the results by Hong et al. (2014) for the provinces of China. The authors model the effect of agglomeration of creative industries (using a location quotient for creative industries) on total factor productivity (TFP) growth, finding that an increase of $100 \%$ in specialisation in creative industries increases TFP by about $4 \%$. They also find evidence that the whole effect is due to the impact of creative industries on technological progress, whereas their effect on changes in technical efficiency was not significant. Boix and Soler (2017) also provided evidence that about $90 \%$ of the impact of the creative industries on the productivity of the EU regions was indirect, due to their spillover effects on the economy.

Some of these works discuss the implications or sensibility of the results to the empirical definition of creative industry and, in particular, the effect of the different creative industries on the productivity or the wealth. Boix et al. (2013) and Boix and Soler (2017) find robust evidence that only creative service industries have a positive and relevant effect on the differences of wealth between the regions of the European Union, whereas the aggregated effect of the so-called creative manufacturing industries tends to be null or negative.

Boix et al. (2013) disaggregated the correlations of individual creative sectors with the wealth of the European regions, finding that the correlation is positive for all the creative sectors, being particularly high for Publishing, Computer programming, Advertising, Architecture and engineering, creative Research and development and Creative retail. The correlation is lower for Broadcasting, Design and photography, and Arts, entertainment and recreation. 


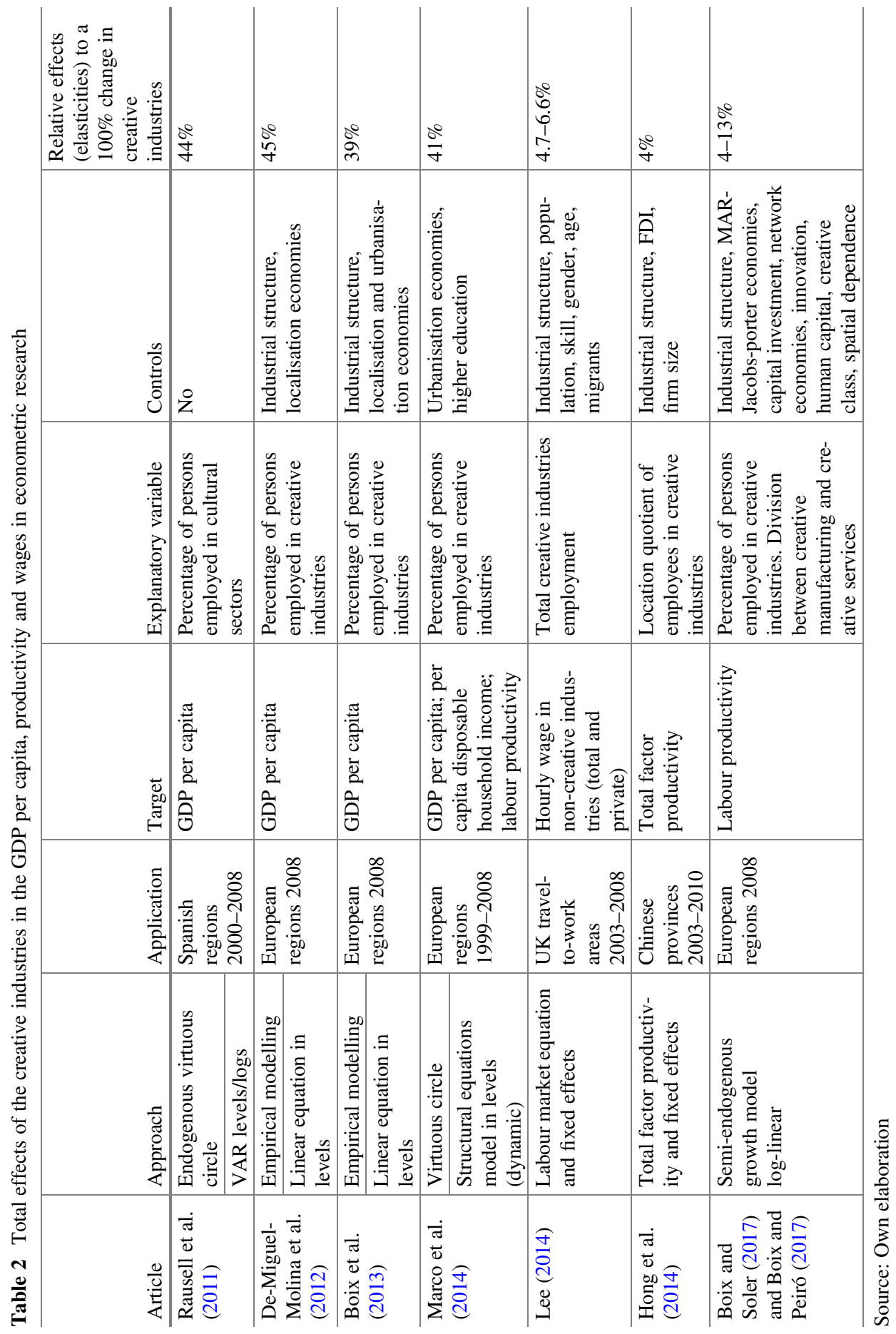




\section{Conclusions}

This paper focuses on the economic impact of the creative industries in the economy of the European Union, differentiating between direct and total effects. The review of the literature measuring both types of impacts suggests the following conclusions:

(a) The creative industries have relevant direct and indirect effects in the economy of the EU (see KEA 2006; Power and Nielsén 2010; TERA 2010, 2012; EY 2014; Boix and Soler 2017). They have a direct contribution to employment, which ranges from $2.6 \%$ of the production and employment in the most conservative delimitations based on a culture-based approach, to $7.8 \%$ of the production and employment using comprehensive delimitations, such as those based on UNCTAD $(2008,2010)$.

(b) However, the creative industries not only have direct effects but also generate spillovers that affect the rest of the European economy through indirect, induced and evolutionary mechanisms (see Rausell et al. 2011; De-Miguel-Molina et al. 2012; Marco et al. 2014; Boix et al. 2013; Boix and Soler 2017). These mechanisms include supply and demand effects on production growth, and in particular, indirect effects related to the capacity of the creative industries to create technical progress and modify the evolutionary growth path of the economy. The initial measurement of these effects resulted in extremely high responses of the EU economy-elasticities of more than $40 \%$ - to increases in the contribution of creative industries to employment. However, these elasticities were hard to believe, and later research using more robust theoretical models and controlling the specification biases has proven that the response elasticities would be in a range of between 4 and $13 \%$, which continues to be a high impact and deserves the attention of economic policies.

(c) Most of this contribution is due to the creative service industries, whereas the direct contribution of the creative manufacturing industries is small and the total contribution, including direct and indirect effects, could be negative. The direct contribution of the creative manufacturing industries does not exceed $1 \%$ of the GDP and $1.6 \%$ of the employment. Labour productivity of the creative manufacturing sector is about half of the EU average, whereas labour productivity of creative services is slightly higher than the EU average. The econometric estimates by Boix et al. (2013) and Boix and Soler (2017) show that higher levels of creative manufacturing reduce the labour productivity of the regions, whereas higher levels of creative service industries have a multiplying effect on the regional labour productivity in the EU.

Due to space limitations, this paper has not focused on the direct measurement of the relationship between creative industries and other variables such as innovation, foreign direct investment and exports of goods and services (especially tourism). In any case, the evidence at the European level about both is still small and is one of the fields in which more research is needed. 
In fact, one final conclusion of this paper would be that the evidence on the effects of the creative industries on the EU economy is still very limited and needs much more research. We suggest some of the priority research lines. First, the measurement of the differences in economic impact of the creative industries for Mediterranean, Eastern, Central and Nordic regions needs study, as does the comparison with the effects for non-European countries. Second, research is needed on the measurement of the effects of the creative industries on the well-being of the EU economies, including their economic implications, to satisfy the cultural and creative rights of its citizens, which is the fastest way to enhance their utility through pleasure, engagement and meaning (see Rausell 2018). Third, we are lacking studies on the use of time-dynamic models, which is, however, limited by the current state of the statistics. Fourth, an approach that has been scarcely studied in the literature is the role of demand. The number of people employed in the cultural and creative sector determines the power of a solvent demand that is very prone to innovation and therefore becomes a promoter of social and political innovation. This is not only due to an income effect, as the creative class is also manifested through a particular lifestyle that involves consuming more innovative products and services and creative content. Fifth, in addition to the empirical measurements, we should move towards a complex and comprehensive conceptual model that considers all the relationships analysed.

\section{References}

Asheim BT, Parrilli MD (2012) Introduction: learning and interaction-drivers for innovation in current competitive markets. In: Asheim BT, Parrilli MD (eds) Interactive learning for innovation: a key driver within clusters and innovation systems. Palgrave Macmillan, Basingstoke, pp $1-32$

Asheim B, Boschma R, Cooke P (2011) Constructing regional advantage: platform policies based on related variety and differentiated knowledge bases. Reg Stud 45:893-904

Bakshi H, McVittie E (2009) Creative supply-chain linkages and innovation: do the creative industries stimulate business innovation in the wider economy? Innov Manag Policy Pract 11:169-189

Baumol WJ, Bowen W (1965) On the performing arts: the anatomy of their economic problems. Am Econ Rev 55:495-502

Boix R (2012) Creative industries in Spain: the case of printing and publishing. In: Lazzeretti L (ed) Creative industries and innovation in Europe: concepts, measures and comparative case studies. Routledge, Abingdon, pp 65-85

Boix R, Peiró J (2017) Industrias de servicios creativos y productividad del trabajo en las regiones de la Unión Europea. In: Valdivia M, Cuadrado JR (eds) La economía de las actividades creativas: Una perspectiva desde España y Mexico, 1st edn. Universidad Nacional Autónoma de México and Universidad de Alcalá de Henares, Madrid, pp 357-380

Boix R, Soler V (2017) Creative service industries and regional productivity. Pap Reg Sci 96 (2):261-279

Boix R, De Miguel B, Hervás JL (2013) Creative service business and regional performance: evidence for the European regions. Serv Bus 7(3):381-398

Chapain C, Cooke P, Propris LD, MacNeill S, Mateos-García J (2010) Creative clusters and innovation. NESTA Research Report, London 
Coll V, Pardo C, Caballer M (2018) Cultural statistics in Europe. In: Paper presented at the II forum in cultural economics. Two points in the silk road. Transmaking Spring Academy, University of Valencia, 5-8 Mar 2018

Cooke P, De Propris L (2011) A policy agenda for EU smart growth: the role of creative and cultural industries. Policy Stud 32(4):365-375

DCA (1994) Creative nation: Commonwealth cultural policy. DCA, Canberra

DCMS (1998) The creative industries mapping document. DCMS, London

DCMS (2001) Creative industries mapping document 2001. DCMS, London

DCMS (2009) Creative industries economic estimates statistical bulletin January 2009. DCMS, London

De-Miguel-Molina B, Hervás JL, Boix R, De-Miguel-Molina M (2012) The importance of creative industry agglomerations in explaining the wealth of European regions. Eur Plan Stud 20 (8): $1263-1280$

Dolfman ML, Holden RJ, Fortier Wasser S (2007) The economic impact of the creative arts industries: New York and Los Angeles. Month Lab Rev (Oct):21-34

EUIPO (2016) Intellectual property rights intensive industries and economic performance in the European Union. EUIPO, Munich

European Parliament (2016) Report on a coherent EU policy for cultural and creative industries (2016/2072(INI)). European Parliament, Brussels

EY (2014) Creating growth: measuring cultural and creative markets in the EU. EY, France

Foray D, Goddard J, Beldarrain XG, Landabaso M, McCann P, Morgan K and Ortega-Argilés R (2012) Guide to research and innovation strategies for smart specialisations (RIS 3). European Commission, DG Regional Policy

Hesmondhalgh D (2010) User-generated content, free labour and the cultural industries. Ephemera 10(3/4):267-284

Higgs P, Cunningham S (2008) Creative industries mapping: where have we come from and where are we going? Creat Industr J 1(1):7-30

Hong J, Yu W, Guo X, Zhao D (2014) Creative industries agglomeration, regional innovation and productivity growth in China. Chin Geogr Sci 24(2):258-268

Horkheimer M, Adorno TW (2002) Dialectic of enlightenment. Philosophical Stanford University Press, Stanford

Inglehart RF (2018) Cultural evolution: people's motivations are changing, and reshaping the world. Cambridge University Press, Cambridge

KEA (2006) The economy of culture in Europe. European Commission Directorate-General for Education and Culture, Brussels

Lazzeretti L, Boix R, Sánchez D (2018) Entrepreneurship and creative industries in developing and developed countries. In: Lazzeretti L, Vecco M (eds) Creative industries and entrepreneurship: paradigms in transition from a global perspective. Edward Elgar, Cheltenham, pp 35-57

Lee N (2014) The creative industries and urban economic growth in the UK. Environ Plan A 46:455-470

LEG Eurostat (2000) Cultural statistics in the EU, Eurostat working paper, population and social conditions series, 3/2000/E/No1, final report of the LEG. Eurostat, Luxembourg

Marco F, Rausell P, Abeledo R (2014) Economic development and the creative industries: a Mediterranean tale of causality. Creat Industr J 7(2):81-91

Nathan M, Pratt A, Rincón-Aznar A (2015) Creative economy employment in the EU and the UK: a comparative analysis. NESTA, London

O'Connor J (2007) The cultural and creative industries: a review of the literature. Arts Council England, London

Potts J (2009) Why creative industries matter to economic evolution. Econ Innov New Technol 18 (7-8):663-673

Potts J, Cunningham S (2008) Four models of the creative industries. Int J Cult Policy 14 (3):233-247

Power D, Nielsén T (2010) Priority sector report: creative and cultural industries. ECO, Stockholm 
Rausell P (2018) Culture, creativity and economic progress. In: Mickov B, Doyle JE (eds) Culture, innovation and the economy, 1st edn. Routledge, Abingdon, pp 3-5

Rausell P, Marco F, Abeledo R (2011) Sector cultural y creativo y riqueza de las regiones: en busca de causalidades. Ekonomiaz 78:67-89

Sacco PL, Segre G (2006) Creativity, cultural investment and local development: a new theoretical framework for endogenous growth. In: Fratessi U, Senn L (eds) Growth and innovation in competitive regions: the role of internal and external connections. Springer, Berlin, pp 281-294

TERA Consultants (2010) Building a digital economy: the importance of saving jobs in the EU's creative industries. Tera, Paris

TERA Consultants (2012) The economic contribution of the creative industries to EU GDP and employment. Tera, Paris

Throsby D (2008) Modelling the cultural industries. Int J Cult Policy 14(3):217-232

UNCTAD (2008) Creative economy. Report 2008. UNCTAD, Geneva

UNCTAD (2010) Creative economy. Report 2010. UNCTAD, Geneva

UNESCO (2009) The 2009 UNESCO framework for cultural statistics (FCS). UNESCO, Geneva

UNESCO (2012) Measuring the economic contribution of cultural industries. UNESCO, Geneva

WIPO (2003) Guide on surveying the economic contribution of the copyright industries. WIPO, Geneva

WIPO (2014) WIPO studies on the economic contribution of the copyright industries. WIPO, Geneva

Yu W, Hong J, Zhu MD, Guo X (2014) Creative industry clusters, regional innovation and economic growth in China. Reg Sci Policy Pract 6(4):329-347

Open Access This chapter is licensed under the terms of the Creative Commons Attribution 4.0 International License (http://creativecommons.org/licenses/by/4.0/), which permits use, sharing, adaptation, distribution and reproduction in any medium or format, as long as you give appropriate credit to the original author(s) and the source, provide a link to the Creative Commons license and indicate if changes were made.

The images or other third party material in this chapter are included in the chapter's Creative Commons license, unless indicated otherwise in a credit line to the material. If material is not included in the chapter's Creative Commons license and your intended use is not permitted by statutory regulation or exceeds the permitted use, you will need to obtain permission directly from the copyright holder.

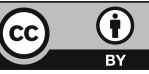

